\title{
Storage Does Not Influence Steryl Glucoside Concentration in Cycas micronesica Seeds
}

\author{
Thomas E. Marler ${ }^{1}$ \\ College of Natural and Applied Sciences, University of Guam, UOG Station, \\ Mangilao, Guam 96923
}

Vivian Lee and Christopher A. Shaw
Department of Ophthalmology, University of British Columbia, Vancouver,
British Columbia, V5Z 1 L8 Canada

Additional index words. ALS-PDC, Cycas micronesica, Guam, seed chemistry

\begin{abstract}
The concentration of two steryl glucosides and their sterol precursors were measured in gametophyte tissue of Cycas micronesica K.D. Hill seeds before and after two storage treatments. For one study, intact 14-month-old seeds were stored at room temperature for 10 months. For the second study, cleaned (sarcotesta tissue removed) 22-month-old seeds were sown in perlite propagation beds, and ungerminated seeds were harvested after 14 months. Concentration of the steryl glucosides and sterols in the gametophyte tissue did not differ between the fresh seeds and the seeds after storage. The function of these metabolites is not known, but their unexpected stability for up to 14 months of storage indicates they are not metabolized during storage and may be vital during germination and early seedling growth. Implications on human exposure to their neurotoxic effects from gametophyte flour ingestion are discussed.
\end{abstract}

Cycads are considered basal-to-extant spermatophytes. Their stalwart biological presence contrasts sharply with the list of sympatric taxa that have come and gone throughout evolutionary time. The competitive and facilitative benefits imparted by an abundant supply of secondary metabolites may be partly responsible for the unwavering presence of cycads through modern times (Norstog and Nicholls, 1997). Although plant function of the identified cycad metabolites remains elusive to date (Brenner et al., 2003), several of them are acutely carcinogenic or neurotoxic to vertebrate consumers (Norstog and Nicholls, 1997; Whitelock, 2002).

Most contemporary cycad species are spectacular horticultural specimens. Cycas revoluta Thunb. has attained national and international popularity in the landscape and nursery industries. Cycas rumphii Miquel and Zamia furfuracea Aiton are also common but are less popular than C. revoluta internationally. Despite their horticultural appeal, the rest of the roughly 300 cycad species (see Hill and Stevenson, 2006) remain obscure except on a regional scale. We suggest that

\footnotetext{
Received for publication 18 Oct. 2006. Accepted for publication 18 Nov. 2006.

Support provided by USDA CSREES Tropical and Subtropical Agricultural Research Grants Program (2003-05495) to T.E.M. and U.S. Army Medical Research and Materiel Command (DAMD17-02-10678), NSERC Canada, and Scottish Rite Charitable Foundation of Canada to C.A.S.

We thank J. Chung and N. Dongol for assistance. ${ }^{1}$ To whom reprint requests should be addressed; e-mail tmarler@uog.edu.
}

one way to increase representation of cycads in the horticultural trade is to further the study of their physiological and horticultural requirements.

Guam's Cycas micronesica K.D. Hill is the island's only native gymnosperm and America's only native Cycas species. Exposure to secondary metabolites that act as neurotoxins via direct ingestion of seed gametophyte tissue from this cycad is a strong epidemiological correlate for the high incidence of the diseases known as amyotrophic lateral sclerosis/parkinsonism-dementia complex (ALS/PDC) (Kurland, 1993; Marler et al., 2005a). Ingestion of this cycad flour was a prevalent part of the local diet throughout historic times. We have been studying a group of phytosteryl glucosides and their sterol precursors because they elicit cell death in neural cell cultures and spinal motor neuron loss in mice studies (Khabazian et al., 2002; Shaw et al., 2007). Our recent focus has been to understand more fully the environmental and anthropogenic factors that influence biosynthetic and allocational plasticity of these compounds and the genetic, developmental, or biogeographical constraints on that phenotypic plasticity (Marler et al., 2005a, 2005b, 2006b).

Our objectives for this communication were to define the role of seed storage on the phenotypic expression of these metabolites. We hypothesized the sterols and steryl glucosides would decline during storage in accordance with the decline that occurs throughout seed development before natural abscission (Marler et al., 2006b). Furthermore, we hypothesized that the sterol precursors would decline more than the steryl glucosides because any continuation of sterol conversion to steryl glucoside would occur without the opportunity to import internal plant resources to maintain the sterol pool in the gametophyte tissue.

\section{Materials and Methods}

Experiment 1. Seeds were harvested from one plant in southern Guam in Feb. 2004 from sporophylls that emerged 22 months prior. Sarcotesta tissue was removed in preparation for sowing. To quantify chemistry of these newly collected seeds, we used composite samples of gametophyte tissue from four randomly selected seeds for each of 10 replications (40 seeds total). The tissue was prepared and frozen as described by Marler et al. (2005b). The remaining seeds were sown on $19 \mathrm{Feb} .2004$ in beds of perlite and maintained at constant $24{ }^{\circ} \mathrm{C}$ and photosynthetic photon flux $(P P F)$ of 30 $\mu \mathrm{mol} \cdot \mathrm{m}^{-2} \cdot \mathrm{s}^{-1}$ for $12 \mathrm{~h} \cdot \mathrm{d}^{-1}$. We used aerosol misters to maintain $100 \%$ humidity in the germination beds, which were large flat plastic containers covered with polypropylene. As seeds germinated, they were transferred to a nursery. For this experiment, we were interested in chemistry of the many seeds that remained in the seed beds in Apr. 2005 awaiting germination. Thus we selected random samples on 15 Apr. 2005 in accordance with methods in Feb. 2004 to provide 10 replications composed of four seeds each. All samples were lyophilized and analyzed by reversed phase HPLC analysis as described by Marler et al. (2005b).

Experiment 2. Seeds were harvested in May 2004 from 10 C. micronesica individuals in northwest Guam from sporophylls that emerged 14 months prior. Although natural abscission may occur later than 30 months following sporophyll emergence, prior experience indicated postharvest embryo development of $C$. micronesica seeds this age would continue in storage (see Dehgan and Shutzman, 1989). Seeds were harvested and sorted according to north-, south-, east-, and west-oriented zones for each plant. Gametophyte tissue from two seeds per zone was combined into one composite sample for each plant and frozen. Thus, each replication for these prestorage samples was represented by eight seeds, and the overall mean was represented by 80 seeds. The remaining seeds were stored intact in open air at $24{ }^{\circ} \mathrm{C}, 80 \%-90 \%$ relative humidity, and $P P F$ of $30 \mu \mathrm{mol} \cdot \mathrm{m}^{-2} \cdot \mathrm{s}^{-1}$ for $12 \mathrm{~h} \cdot \mathrm{d}^{-1}$ until Mar. 2005. Tissue preparation from two seeds per zone for each plant was repeated in accordance with the May 2004 sampling. All samples were lyophilized and analyzed as above. Data from both experiments were subjected to analysis of variance.

\section{Results}

Concentration of stigmasterol $\beta$-D-glucoside (SG) and $\beta$-sitosterol $\beta$-D-glucoside (BSSG) were similar for the fresh seeds, and 10 months of storing seeds elicited 
no change in concentration of either steryl glucoside ( $F$ test, Fig. 1). Gametophyte concentrations of the sterols $\beta$-sitosterol (BSS) and stigmasterol (SS) were also unaffected by this lengthy seed storage treatment.

Gametophyte concentration of BSSG was elevated above that of SG, SS, and BSS for the fresh seeds (Fig. 2). However, storage for 14 months under conditions suitable for germination did not influence concentration of the measured metabolites ( $F$ test, Fig. 2).

\section{Discussion}

We predicted a decline in steryl glucosides during 10 months of storing intact 14-month-old seeds on the basis of the known decline of these metabolites over the 14- to 24-month period for preharvest seeds (Marler et al., 2006b). Results were inconsistent with this prediction. Further, we predicted an even greater decline in the sterols in these stored seeds due to inability to import internal plant resources to sustain sterol biosynthesis. Results were inconsistent with this prediction as well. The results indicate that metabolism of these metabolites was stifled as a consequence of harvest and that the pool of metabolites at harvest was remarkably stable throughout 10 months of storage.

We also expected steryl glucosides and sterols to decline in seeds prepared for germination and sown in germination beds. The storage conditions for these seeds differed from the storage conditions of the intact seeds because the environment was suitable for advancement of all physiological

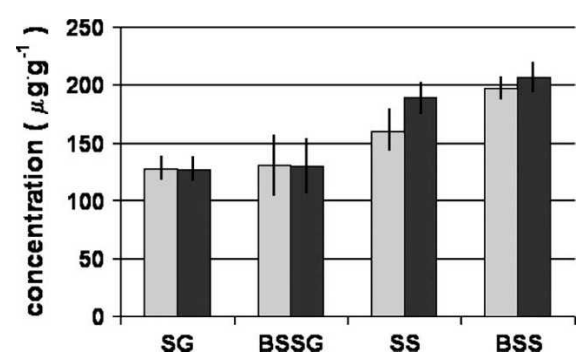

Fig. 1. Gametophyte concentration of SG, BSSG, BSS, and SS of 14-month-old C. micronesica seeds before (light shading) or after 10 months of storage (dark shading). Mean $\pm \mathrm{SE}, \mathrm{n}=10$.

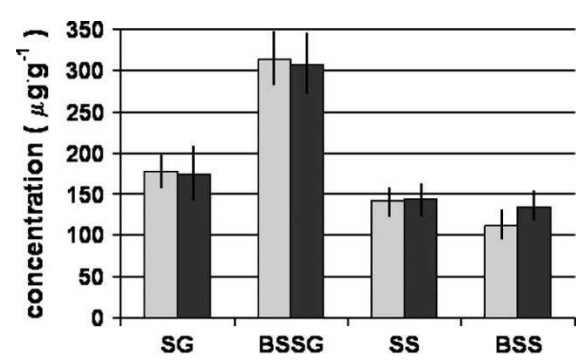

Fig. 2. Gametophyte concentration of SG, BSSG, BSS, and SS of 22-month-old C. micronesica seeds before (light shading) or after 14 months of storage (dark shading) in conditions suitable for germination. Mean $\pm \mathrm{sE}, \mathrm{n}=10$. germination processes. These seeds also differed from the stored intact seeds in that sarcotesta was removed. The sarcotesta is analogous to pericarp tissue of some fruit species, in that it protects embryo and storage tissue and prevents germination. Cantatore et al. (2000) proposed that steryl glucosides serve as resource donors, and sarcotesta tissue is heavily endowed with BSSG and SG (Marler et al., 2005b). Thus the presence or absence of sarcotesta tissue could strongly influence the allocational plasticity of the sterols and steryl glucosides among all seed tissues during storage. Results of this study were also inconsistent with our expectations. Under favorable conditions for germination, the steryl glucosides and sterols within gametophyte tissue of these seeds remained stable for 14 months.

$A L S / P D C$ relevance. The historical process of harvesting $C$. micronesica seeds for the purpose of preparing flour for human consumption was indiscriminate (Marler et al., 2005a, 2006b). Harvesters of these seeds collected any seed with brown phenotype, whether it was from trees or the ground. Our results indicate the seeds harvested from the ground contained greater concentrations of neurotoxic steryl glucosides than seeds of similar age harvested from trees. Guam is frequently impacted by tropical cyclones known locally as typhoons (Marler, 2001). Major typhoons cause considerable structural damage to Guam's plants, and minor typhoons elicit leaf, fruit, and seed abscission. This study reveals the probability that ephemeral post-typhoon periods were characterized by increased exposure to C. micronesica seed neurotoxins due to the increased percentage of seed collection from the ground.

Horticultural relevance. The arborescent cycad species are represented by striking specimen plants. The beautiful pinnately compound leaves are borne in attractive radial symmetry on a columnar stem. The cones are sometimes massive, sometimes brightly colored, but they are always remarkable and conspicuous morphological features that add to the horticultural appeal. The antiquity and primitive features of cycad species provide even more attributes of interest to horticulturists. The study of their mycorrhizal and cyanobacteria symbiotic relationships (Marler et al., 2005a) and obligate pollinator systems (Norstog and Nicholls, 1997) may give insights into the evolution of early pollination systems and mutualisms of all types, especially in light of plant diversification.

Cycad horticulturists are knowledgeable about the necessity of seed storage following harvest of many species (Whitelock, 2002). The embryo does not develop to full size until after harvest for these species. Removing sarcotesta and sowing seeds before embryo development is a common cause of germination failure for growers lacking experience. The literature on seed physiology (including chemistry) during production and storage is extensive for agronomic and horticultural crops (e.g., Bewley and Black, 2004; Desai, 2004). The literature on the ecological and evolutionary importance of seed dormancy and environmental conditions needed to enable successful germination is also substantial (e.g., Donohue, 2005). Despite this publication history on a host of species, we are unaware of any prior studies that have addressed the influence of storage or germination on the chemical relations of cycad seeds.

The need for this research is critical for the roughly half of described cycad species that the IUCN has listed as threatened or endangered (IUCN, 2006). Clarifying the biochemical constraints on germination is hindered by the rarity of seeds available for manipulative studies. Utmost stability of the sterol and steryl glucoside pool in C. micronesica gametophyte tissue following harvest was unexpected. These steryl glucosides may serve as assimilate donors (discussed in Marler et al., 2005a). For this function, our results indicate that maintenance of seed health during storage is not a phase that requires those assimilates. These metabolites may also serve as primers for cellulose synthesis (Peng et al., 2002). Certainly copious cellulose biosynthesis is not needed during seed storage, so the stability of the steryl glucosides may be an effective approach to sustaining gametophyte resources for cellulose biosynthesis upon germination. Further studies throughout germination and early seedling growth would determine if the highly stable steryl glucoside pool in C. micronesica gametophyte tissue is metabolized or redistributed among the expanding seedling organs.

One pragmatic reason for aggressively studying the link between $C$. micronesica toxins and ALS/PDC is that increased use of this striking plant in the horticultural industry is restrained by this purported link. Unfortunately, the population of this endemic species has deteriorated from one of the most abundant forest species to being "red-listed" as endangered by the IUCN (Marler et al., 2006a) because of the assault by the invasive scale, Aulacaspis yasumatsui Takagi (Haynes, 2006; Marler and Muniappan, 2006). The urgency of continued research to prove or disprove the link between cycad toxins and ALS/PDC is more critical now that the island's natural population is headed toward possible extinction. The potential for conservation of the species within horticultural plantings adds an even greater need for removing all obstacles that are keeping the species from increased use within the horticulture industry.

\section{Literature Cited}

Bewley, J.D. and M. Black. 2004. Seeds: physiology of development and germination. 2nd ed. Plenum Publishing Corporation, New York.

Brenner, E.D., D.W. Stevenson, and R.W. Twigg. 2003. Cycads: evolutionary innovations and the role of plant-derived neurotoxins. Trends Plant Sci. 8:446-452.

Cantatore, J.L., S.M. Murphy, and D.V. Lynch. 2000. Compartmentation and topology of 
glucosylceramide synthesis. Biochem. Soc. Trans. 28:748-750.

Dehgan, B. and B. Schutzman. 1989. Embryo development and germination of Cycas seeds. J. Amer. Soc. Hort. Sci. 114:125-129.

Desai, B.B. 2004. Seeds handbook: biology, production, processing, and storage. 2nd ed. Marcel Decker, New York.

Donohue, K. 2005. Niche construction through phenological plasticity: life history dynamics and ecological consequences. New Phytol. 166:83-92.

Haynes, J. 2006. Cycad Aulacaspis scale information page. The World Conservation Union, Gland, Switzerland. 7 Dec. 2006. http:// www.iucn.org/themes/ssc/sgs/csg/pages/ CAS.htm.

Hill, K.D. and D.W. Stevenson. 2006. World list of cycads. Royal Botanic Gardens. Sydney, Australia, 7 Dec. 2006. http://plantnet.rbgsyd. gov.au/PlantNet/cycad/wlist.html.

IUCN. 2006. IUCN red list of threatened species. IUCN Species Survival Commission, Gland, Switzerland. 7 Dec. 2006. http://www.redlist. org.

Khabazian, I., J.S. Bains, D.E. Williams, J. Cheung, J.M.B. Wilson, B.A. Pasqualotto,
S.L. Pelech, R.J. Andersen, Y.-T. Wang, L. Liu, A. Nagai, S.U. Kim, U.-K. Craig, and C.A. Shaw. 2002. Isolation of various forms of steryl $\beta$-D-glucoside from the seed of Cycas circinalis: neurotoxicity and implications for ALS-parkinsonism dementia complex. J. Neurochem. 82:516-528.

Kurland, L.T. 1993. Cycas circinalis as an etiologic risk factor in amyotrophic lateral sclerosis and other neurodegenerative diseases on Guam, p. 29-36. In: D.W. Stevenson and K.J. Norstog (eds.). Proc. Cycad 90, Second Int. Conf. on Cycad Biology. Palm and Cycad Societies of Australia, Ltd., Milton, Queensland.

Marler, T.E. 2001. Tropical cyclones and perennial species in the Mariana Islands. HortScience 36:264-268.

Marler, T.E. and R. Muniappan. 2006. Pests of Cycas micronesica leaf, stem, and male reproductive tissues with notes on current threat status. Micronesica 39:1-9.

Marler, T.E., V. Lee, and C.A. Shaw. 2005a. Cycad toxins and neurological diseases in Guam: defining theoretical and experimental standards for correlating human diseases with environmental toxins. HortScience 33:1598-1606.
Marler, T.E., V. Lee, and C.A. Shaw. 2005b. Spatial variation of steryl glucosides in Cycas micronesica plants: within- and among-plant sampling procedures. HortScience 40:1607-1611.

Marler, T., J. Haynes, and A. Lindström. 2006a. Cycas micronesica. In: IUCN red list of threatened species. 7 Dec. 2006. http://www. redlist.org.

Marler, T.E., V. Lee, J. Chung, and C.A. Shaw. 2006b. Steryl glucoside concentration declines with Cycas micronesica seed age. Funct. Plant Biol. 33:857-862.

Norstog, K.J. and T.J. Nicholls. 1997. The biology of the cycads. Cornell Univ. Press, New York.

Peng, L., Y. Kawagoe, P. Hogan, and D. Delmer. 2002. Sitosterol- $\beta$-glucoside as primer for cellulose synthesis in plants. Science 295: 147-150.

Shaw, C.A., J.M.B. Wilson, R. Cruz-Aguado, S. Singh, E.L. Hawkes, V. Lee, and T. Marler. 2007. Cycad-induced neurodegeneration in a mouse model of ALS-PDC: is the culprit really BMAA or is a novel toxin to blame? Memoirs of the New York Botanical Garden. (in press).

Whitelock, L.M. 2002. The cycads. Timber Press. Portland, Ore. 